\title{
Regulating prescription drugs for patient safety: Does Bill C-17 go far enough?
}

\author{
Matthew Herder JSM LLM, Elaine Gibson LLM, Janice Graham PhD, Joel Lexchin MSc MD, \\ Barbara Mintzes PhD
}

$\mathrm{C}$ anada was the last developed country in the world to remove thalidomide from the market, and doing so required an Act of Parliament. At the request of Health Canada's then Food and Drug Directorate, thalidomide's two manufacturers voluntarily withdrew the drug from the market on Mar. 2, 1962. ${ }^{1}$ However, most of the drug's distribution was in the form of free samples to medical professionals, which the directorate had no legal authority to control. ${ }^{2}$ Therefore, to avoid similar situations in the future and to stop sales of thalidomide, on Dec. 4, 1962, the Parliament of Canada amended the Food and Drugs Act, allowing the distribution of drug samples only under "prescribed conditions" and prohibiting the sale of any drug listed in Schedule $\mathrm{H}$ of the act, including thalidomide. ${ }^{3}$ The legislation stopped short of granting legal authority to the directorate to unilaterally recall drugs, even though officials recognized that "the co-operation of the manufacturer to recall a drug from the market could not be solely relied on."

More than 50 years later, this gap in Canada's Food and Drugs $\mathrm{Act}^{4}$ remains: the regulator, Health Canada, cannot order a drug recall. Instead, it must negotiate drug recalls with manufacturers. Negotiation invites delay ${ }^{5}$ and may precipitate harm to patients that could have been avoided. Several recent examples, including the acne drug cyproterone acetate-ethinyl estradiol (Diane-35), ${ }^{6}$ the diabetes drug rosiglitazone (Avandia), the pain-relief drug propoxyphene (Darvon-N), the gastroesophageal reflux drug cisapride (Prepulsid), and the anti-inflammatory drug rofecoxib (Vioxx), illustrate the adverse consequences that may flow from manufacturers' indecision about whether and when to issue a recall, and the regulator's inability to compel one. (Table 1 lists drugs withdrawn for safety reasons from the Canadian market after Aug. 1, 2004.) Drug withdrawals are relatively rare in Canada. However, the fact that some of those withdrawn had been very widely prescribed means that tens of thousands of Canadians were exposed to potential harm after safety issues first arose but before market withdrawal. ${ }^{7}$
Bill C-17, An Act to Amend the Food and Drugs Act, was introduced into Parliament on Dec. 6, 2013, and promises to finally fix this fundamental flaw in Canada's legislation. Proposing revisions to the Food and Drugs Act, including the addition of a power to recall drugs, the bill has been dubbed the Protecting Canadians from Unsafe Drugs Act (Vanessa's Law). (Table 2 summarizes Bill C-17's key provisions.) If enacted, Bill C-17 would represent a substantial improvement over the status quo. Yet, Bill C-17 by no means offers a comprehensive solution to the many problems that have plagued the development, regulation and safe use of prescription drugs in the 50-plus years since thalidomide was withdrawn from the market. Drug manufacturers have engaged in selective reporting to regulators about the evidence base behind new drugs, thereby enhancing the likelihood of receiving market approval. ${ }^{8}$ Moreover, a close-knit, conflicted relationship has been observed to exist between manufacturers and regulators at times. ${ }^{9-11}$ Therefore, in addition to outlining four elements of the proposed legislation that are welcome improvements to the status quo, we detail six critical elements to add to Bill C-17 to further fulfill the bill's core goal of protecting patient safety.

\section{Important and welcome elements in the proposed legislation}

\section{Power to recall drugs}

Bill C-17 empowers the Health Minister to issue a recall, without first entertaining representations from the manufacturer, provided he or she

\section{- Ker POINTS}

- Bill C-17, An Act to Amend the Food and Drugs Act, was introduced into Parliament by the federal government on Dec. 6, 2013.

- If enacted, Bill C-17 would give Health Canada the legal power to recall drugs.

- To meet Bill C-17's core goal of ensuring patient safety, key provisions to improve the transparency of clinical trials and regulatory decisionmaking must be added to the proposed legislation.
Competing interests: In 2008 Joel Lexchin was an expert witness for the Canadian government in its defence of a lawsuit challenging the ban on direct-to-consumer advertising of prescription drugs. In 2010 he was an expert witness for a law firm representing the family of a plaintiff who allegedly died from a drug made by Allergan. No other competing interests were declared.

This article has been peer reviewed.

Correspondence to:

Matthew Herder, matthew.herder@dal.ca

CMAJ 2014. DOI:10.1503 /cmaj.131850 
"believes that a therapeutic product presents a serious or imminent risk of injury to health." Currently, the Health Minister may suspend a manufacturer's licence to sell a drug, ${ }^{12}$ but he or she cannot require the drug to be removed (i.e., recalled) from pharmacy shelves. Only the manufacturer can do so. This parallels the present situation in the United States. ${ }^{13}$ The voluntary nature of drug recalls in both jurisdictions has, on occasion, precipitated harmful delays and may undermine regulators' ability to communicate safety information to the public in a timely fashion. Thus, we contend that Bill C-17's recall provision constitutes an essential addition to the Health Minister's powers and should be lauded.

\section{Power to overcome information asymmetries}

Bill C-17 enables the Health Minister to compel manufacturers to provide information about drugs. This is a crucial function because manufacturers are likely to have the greatest realtime knowledge about the safety and effectiveness of the drugs they market. ${ }^{14}$ One proposed amendment states, "If the Minister believes that a therapeutic product may present a serious risk of injury to human health, the Minister may order a person to provide the Minister with information ... to determine whether the product presents such a risk." Similarly, another proposed provision requires health care institutions to provide information "about a serious adverse drug reaction that involves a therapeutic product or a medical device incident that involves a therapeutic product." These information-sharing requirements are a major improvement on the status quo.

\section{Power to enforce conditions on market authorizations and compel changes to product labels}

Bill C-17 gives the Health Minister powers to enforce conditions associated with any market authorization granted to manufacturers (also known as a "Notice of Compliance with Conditions" 15 as opposed to the standard "Notice of Compliance"). Holders of market authorizations will be required to comply with any "terms and

Table 1. Drugs withdrawn for safety reasons from the Canadian market after Aug. 1, 2004

\begin{tabular}{|c|c|c|c|}
\hline Drug, generic (brand) name & $\begin{array}{l}\text { Approval date or date listed } \\
\text { in the Compendium of } \\
\text { Pharmaceuticals and Specialties* }\end{array}$ & $\begin{array}{l}\text { Withdrawal } \\
\text { datet }\end{array}$ & Reason for withdrawal \\
\hline Rofecoxib (Vioxx) & Oct. 25, 1999 & Sept. 30, 2004 & $\begin{array}{l}\text { Increased relative risk of } \\
\text { cardiovascular events }\end{array}$ \\
\hline Valdecoxib (Bextra) & Dec. 11, 2002 & Apr. 7, 2005 & Life-threatening skin reactions \\
\hline Thioridazine (Mellaril) & 1959 & Sept. 30, 2005 & Cardiac dysrhythmias \\
\hline $\begin{array}{l}\text { Estradiol dienanthate-estradiol benzoate } \\
\text { and testosterone enanthate (Climacteron) }\end{array}$ & 1961 & Oct. 22, 2005 & $\begin{array}{l}\text { Endometrial hyperplasia/ } \\
\text { carcinoma }\end{array}$ \\
\hline Gatifloxacin (Tequin) & Jan. 9, 2001 & June 29, 2006 & $\begin{array}{l}\text { Serious disorders of glucose } \\
\text { metabolism }\end{array}$ \\
\hline Tegaserod (Zelnorm) & Mar. 12, 2002 & Mar. 30, 2007 & $\begin{array}{l}\text { Increase in cardiovascular } \\
\text { ischemic events }\end{array}$ \\
\hline Pergolide (Permax) & June 27, 1991 & Aug. 30, 2007 & Valvulopathy \\
\hline Lumiracoxib (Prexige) & Nov. 2, 2006 & Oct. 3, 2007 & Risk of serious hepatotoxicity \\
\hline Efalizumab (Raptiva) & Oct. 24,2005 & Feb. 22, 2009 & $\begin{array}{l}\text { Progressive multifocal } \\
\text { leukoencephalopathy }\end{array}$ \\
\hline Sibutramine (Meridia) & Dec. 28,2000 & Oct. 8, 2010 & Serious cardiovascular events \\
\hline Dextropropoxyphene (Darvon-N) & 1961 & Nov. 25, 2010 & $\begin{array}{l}\text { Risk of serious abnormal heart } \\
\text { rhythms }\end{array}$ \\
\hline Sitaxsentan (Thelin) & June 19, 2007 & Dec. 15, 2010 & Idiosyncratic hepatotoxicity \\
\hline $\begin{array}{l}\text { Calcitonin (synthetic, salmon) nasal spray } \\
\text { (Miacalcin) }\end{array}$ & July 13, 1992 & Oct. 1, 2013 & Increased rate of malignancies \\
\hline $\begin{array}{l}\text { Meprobamate-containing medicine } \\
\text { (282-MEP) }\end{array}$ & Nov. 1, 1998 & Oct. 28, 2013 & $\begin{array}{l}\text { Risk of overdose, abuse or } \\
\text { misuse }\end{array}$ \\
\hline \multicolumn{4}{|c|}{$\begin{array}{l}\text { *Approval dates are from Health Canada's Notice of Compliance website: www.hc-sc.gc.ca/dhp-mps/prodpharma/notices-avis/index-eng.php. For drugs approved } \\
\text { before Jan. 1, 1991, the date of approval is the date that the product was first listed in the Compendium of Pharmaceuticals and Specialties. } \\
\text { tWithdrawal dates are from Health Canada's MedEffect website: www.hc-sc.gc.ca/dhp-mps/medeff/advisories-avis/prof/index-eng.php. Withdrawal of gatifloxacin } \\
\text { was not mentioned on the MedEffect website but was confirmed on Health Canada's Drug Product Database: www.hc-sc.gc.ca/dhp- } \\
\text { mps/prodpharma/databasdon/index-eng.php. }\end{array}$} \\
\hline
\end{tabular}


conditions of the authorization that are imposed under regulations." This new power is essential given that, since 1998, about one in 14 new prescription pharmaceuticals and biologics have been approved by Health Canada on the condition that they undertake further postmarket stud- ies pursuant to a Notice of Compliance with Conditions (estimate based on annual reports [19982012] from the Therapeutic Products Directorate and the Biologics and Genetic Therapies Directorate, available on request from publications @hc-sc.gc.ca). With regulatory modernization

Table 2. A summary of key provisions in Bill C-17, An Act to Amend the Food and Drugs Act

Focus

Power to recall drugs information asymmetries
Power to overcome

Proposed section(s)

21.3(1) - If the Minister believes that a therapeutic product presents a serious or imminent risk of injury to health, he or she may order a person who sells the product to

(a) recall the product; or

(b) send the product, or cause it to be sent, to a place specified in the order.

21.1 - If the Minister believes that a therapeutic product may present a serious risk of injury to human health, the Minister may order a person to provide the Minister with information that is in the person's control and that the Minister believes is necessary to determine whether the product presents such a risk.

21.6 - No person shall knowingly make a false or misleading statement to the Minister - or knowingly provide him or her with false or misleading information - in connection with any matter under this Act concerning a therapeutic product.

21.8 - A prescribed health care institution shall provide the Minister, within the prescribed time and prescribed manner, with prescribed information that is in its control about a serious adverse drug reaction that involves a therapeutic product or a medical device incident that involves a therapeutic product.

Power to enforce conditions on market authorizations, modify product labels and require assessments, tests, studies, etc.

21.7 - The holder of a therapeutic product authorization shall comply with the terms and conditions of the authorization that are imposed under regulations.

21.2 - The Minister may, if he or she believes that doing so is necessary to prevent injury to health, order the holder of a therapeutic product authorization that authorizes the import or sale of a therapeutic product to modify the product's label or to modify or replace its package.

21.31 - Subject to the regulations, the Minister may order the holder of a therapeutic product authorization to conduct an assessment of the therapeutic product to which the authorization relates and provide the Minister with the results of the assessment.

21.32 - Subject to the regulations, the Minister may, for the purpose of obtaining additional information about a therapeutic product's effects on health or safety, order the holder of a therapeutic product authorization to

(a) compile information, conduct tests or studies or monitor experience in respect of the therapeutic products; and

(b) provide the Minister with the information or the results of the tests, studies or monitoring. 30(1.2)(b) - Without limiting the power conferred by any other subsection of this section, the Governor in Council may make regulations ... authorizing the Minister to impose terms and conditions on authorizations ... including existing authorizations, and to amend those terms and conditions.

Serious enforcement measures

31.2 - Subject to section 31.4, every person who contravenes any provision of this Act or the regulations, as it relates to a therapeutic product, or an order made under any of sections 21.1 to 21.3 is guilty of an offence and liable

(a) on conviction by indictment, to a fine not exceeding $\$ 5000000$ or to imprisonment for a term not exceeding two years or to both; and

(b) on summary conviction, for a first offence, to a fine not exceeding $\$ 250000$ or to

imprisonment for a term not exceeding six months or to both and, for a subsequent offence, to a fine not exceeding $\$ 500000$ or to imprisonment for a term not exceeding 18 months or to both.

31.4 - A person who contravenes section 21.6 , or who knowingly or recklessly causes a serious risk of injury to human health in contravening another provision of this Act or the regulations, as it relates to a therapeutic product, or an order made under any of sections 21.1 to 21.3 is guilty of an offence and liable

(a) on conviction on indictment, to a fine the amount of which is at the discretion of the court or to imprisonment for a term not exceeding five years or to both; and

(b) on summary conviction, for a first offence, to a fine not exceeding $\$ 500000$ or to imprisonment for a term not exceeding 18 months or to both and, for a subsequent offence, to a fine not exceeding $\$ 1000000$ or to imprisonment for a term not exceeding two years or to both.

31.7 - If an offence under section 31.2 or 31.4 is committed or continued on more than one day, it constitutes a separate offence for each day on which it is committed or continued. 
pushing for faster access to drugs, Health Canada is poorly positioned to enforce such postmarket conditions without this new power. ${ }^{16}$ Furthermore, at present it can take several months to negotiate labelling changes despite clear safety concerns. ${ }^{16}$ In 2007, the US Food and Drug Administration (FDA) was granted powers to enforce conditions and to compel changes to a product's label in light of safety concerns that emerge after market approval. ${ }^{17}$ It is imperative that Health Canada be vested with these powers.

\section{Serious enforcement measures}

Finally, Bill C-17 creates much stronger penalties for failure to comply with some of the provisions of the Food and Drugs Act and accompanying regulations. These include fines of up to $\$ 5$ million per day during which the offence is committed, and/or imprisonment for the most egregious offences (e.g., failure by a seller to comply with a recall of a therapeutic product ordered by the Health Minister).

Each of these proposed amendments to the current Food and Drugs Act should be embraced. However, additional elements are badly needed to address patient safety at the federal level.

\section{Elements that should be added to the proposed legislation}

\section{Enhance the power of recall and alter the ability to suspend}

The proposed recall power could be improved in at least three ways. First, the existing power to "suspend" market authorizations (as opposed to issuing a drug recall) for reasons of safety is apparently limited to instances where the Health Minister "considers that the drug is not safe ... as shown by evidence."12 This sets a high bar; in our view, the Health Minister should be empowered to suspend market authorizations where he or she has reasonable grounds to believe a suspension will avoid potential injury to human health. Furthermore, the ability to recall (and suspend) should not be limited to those who sell the product. Elsewhere in Bill C-17, the focus is on holders of "therapeutic product authorizations," so one can infer that sellers and holders of therapeutic product authorizations are not the same entities - the company holding the authorization may, for instance, license distribution to another company. The Health Minister should be explicitly empowered to issue suspensions and recalls to both types of "persons."

Finally, terms such as "injury" and "harm" are open to restrictive interpretation. Health Canada recently took the position that a pregnancy caused by faulty birth control medication is not a "serious adverse health consequence" but rather a "lifestyle choice." ${ }^{18}$ Therefore the medication is in a lower risk classification for recall unless the woman should not get pregnant specifically for medical reasons. ${ }^{19}$ The terminology in Bill C-17 needs to be clarified and definitions provided to prevent such restrictive interpretation.

\section{Exempt the Health Minister from liability for drug suspensions and recalls}

In the event that a market authorization is suspended or a drug recalled, a manufacturer or seller may attempt to sue the government for damage to product sales. This possibility is a strong disincentive to invoking the power to suspend or recall, and may colour the Health Minister's interpretation of when a "potential harm" (for suspensions) or "serious or imminent risk" to health (for recalls) is present. Given the potential difficulties in rapidly establishing a definitive causal link between a given drug and observed adverse events, an exemption from liability for lost product sales or other injury to the manufacturer or seller should be added. This would ensure that the Health Minister can invoke these powers in good faith on a precautionary basis when he or she has reasonable grounds to believe that a drug poses a safety issue and would restrict the ability of a manufacturer or seller to succeed in a lawsuit.

\section{Ensure transparency in clinical trials}

Clinical trial data should be regarded as a public good,$^{20}$ and the need for greater transparency in the evidence base behind therapeutic drugs is well documented. ${ }^{21,22}$ Several jurisdictions including the $\mathrm{US}^{23}$ and Europe ${ }^{24}$ have established a legal requirement to register clinical trials. The European Medicines Agency has announced a proactive policy to release full clinical trial reports submitted by manufacturers for market authorization, ${ }^{25}$ and is exploring the possibility of releasing anonymized patient-specific clinical trial data. Canada has done neither to date. The clinical trials database created last year identifies ongoing clinical trials but does nothing to ensure that the evidence generated by those trials is open to independent and timely scrutiny. ${ }^{26}$ Registration of clinical trials is not a panacea..$^{27,28}$ However, requiring registration by law, and creating a robust mechanism to enforce that requirement, is an important step toward improving the transparency of the evidence base behind drugs and other therapies, and avoiding potential harm to patients. ${ }^{29}$ In addition, making sure that clinical trial data, whether collected before market approval or in postmarket studies, are available for scrutiny by independent researchers is critical 
to ensuring that treatment and use decisions are evidence-based. ${ }^{30}$

\section{Enhance transparency in Health Canada's decision-making}

A related issue is the transparency of Health Canada's own decision-making. At present, Health Canada publishes limited information solely on a subset of its decisions, specifically, on drugs approved for sale and high-risk medical devices. ${ }^{31}$ The European Medicines Agency, in contrast, also publishes its "negative opinions" to ensure that health care providers and patients are aware of drugs not approved for certain indications because of safety or efficacy issues identified during clinical trials. ${ }^{32}$ This aids in averting underinformed off-label prescribing by physicians. The FDA in the US has tabled a proposal to do the same in the name of patient safety. ${ }^{33}$ Bill C-17 should empower Health Canada to publish both positive and negative regulatory decisions. At minimum, Health Canada should publish the rationales for decisions concerning all drugs approved for sale, drugs refused for reasons of safety or efficacy, and drugs that are suspended or recalled. ${ }^{34}$ Presently, the regulator's rationale is not transparent even when drugs are withdrawn from the market for safety reasons, ${ }^{5,35}$ or, conversely, when they remain on the market following a safety review, as with cyproterone acetate-ethinyl estradiol (Diane-35) ${ }^{6}$ or rosiglitazone (Avandia). Bill C-51, which also proposed amendments to the Food and Drugs Act but died on the Order Paper in 2008, included a provision allowing the Health Minister to "disclose to the public information about the risks or benefits that are associated with a therapeutic product." ${ }^{36}$ The omission of such a provision in Bill C-17 must be rectified.

\section{Outline clear limits to the scope of proprietary information}

Meaningful transparency is hard to achieve in practice, in part because manufacturers often claim that the government is obliged to protect information about the safety and efficacy of a drug as "proprietary," either as a "trade secret" or as "confidential business information." ${ }^{37}$ These assertions overstate what the law actually requires and prevent important information about safety and effectiveness from being released. ${ }^{37}$ International treaties simply require Canada to protect trade secrets and confidential business information without specifying the scope of those types of information. No Canadian court decision indicates that information about the safety or efficacy of a drug is proprietary, and current case law casts doubt on any such assertion. In principle, Health
Canada can at present disclose greater amounts of safety and efficacy information. However, to clarify and to overcome manufacturers' efforts to resist disclosure, Bill C-17 should explicitly state that the results of clinical trials, including de-identified patient-level data, postmarket studies, and adverse drug reactions reported by drug manufacturers and health care institutions, are not proprietary and therefore should be publicly disclosed.

The European Medicines Agency was concerned that failure to disclose clinical trial results undermines trust in the regulatory system and ignores the contribution to knowledge generation by clinical trial participants. Therefore, it has taken the stance that trial results are nonproprietary and is moving steadily toward requiring proactive publication of all clinical trial data for drugs it reviews. ${ }^{38}$ Even manufacturers are beginning to acknowledge that, far from undermining innovation, greater disclosure of clinical trial data represents a potential boon to their research and development efforts. ${ }^{39,40}$ It is incumbent on Canada to move in the same direction.

\section{Do not allow trade to trump patient safety}

Bill C-17 gives the Governor in Council scope to impose stringent rules favouring data protection to the detriment of other powers in the Food and Drugs Act. This proposal is fundamentally problematic and must not be enacted. It is true that Canada must, under treaties such as the North American Free Trade Agreement, protect data (including clinical trial data) against "unfair commercial use." ${ }^{41}$ However, under current law there is broad discretion about how to do so, ${ }^{42}$ and any steps taken in the name of data protection are not meant to limit other measures in the Food and Drugs Act that protect patient safety. The Food and Drugs Act should remain as presently worded to preserve the broad discretion of the Health Minister; it should not be amended as proposed in Bill C-17.

\section{Conclusion}

Bill C-17 is an important step toward the safe regulation of drugs because it enhances the ability of Health Canada to act in the face of threats to public health. It also introduces meaningful enforcement mechanisms, including substantial penalties, for noncompliance. However, it requires amendment to incorporate several additional key components of prescription drug safety. Bill C-17 has the potential to make an important and positive difference to public safety in Canada. We urge that Bill $\mathrm{C}-17$ be revised and enhanced before it becomes law so that this potential can be realized. 


\section{References}

1. Webb JF. Canadian thalidomide experience. CMAJ 1963;89: 987-92.

2. Pugsley LI. The administration and development of federal statutes on foods and drugs in Canada. Med Serv J Can 1967;23: 387-449.

3. An Act to Amend the Food and Drugs Act, S.C. 1962, c. 15.

4. Food and Drugs Act, R.S.C., 1985, c. F-27.

5. Lexchin J. Withdrawals of drugs for safety reasons: How do regulators decide if they are too unsafe? Adverse Drug React Bull 2006;236:903-6.

6. Zlomislic D. Risky acne drug Diane-35 underscores Health Canada's limitations. The Toronto Star. 2013 Nov. 9. Available: www.thestar.com/news/canada/2013/11/09/risky_acne_drug_diane 35_underscores_health_canadas_limitations.html (accessed 2014 Feb. 12).

7. Lexchin J. How safe are new drugs? Market withdrawal of drugs approved in Canada between 1990 and 2009. Open Med 2014;8: 14-9.

8. Rising K, Bacchetti P, Bero L. Reporting bias in drug trials submitted to the Food and Drug Administration: review of publication and presentation. PLoS Med 2008;5:e217; discussion e217.

9. Topol EJ. Failing the public health - rofecoxib, Merck, and the FDA. N Engl J Med 2004;351:1707-9.

10. Lexchin J, O'Donovan O. Prohibiting or "managing" conflict of interest? A review of policies and procedures in three European drug regulation agencies. Soc Sci Med 2010;70:643-7.

11. Abraham J, Ballinger R. The neoliberal regulatory state, industry interests, and the ideological penetration of scientific knowledge deconstructing the redefinition of carcinogens in pharmaceuticals. Sci Technol Human Values 2012;37:443-77.

12. Food and Drug Regulations, C.R.C., c. 870, C.08.006(2),

13. 21 C.F.R. 7.40-7.59. Recall policy (2000). Available: www.law .cornell.edu/cfr/text/21/7.40 (accessed 2014 Feb. 12).

14. Lexchin J, Wiktorowicz M, Moscou K, et al. Provincial drug plan officials' views of the Canadian drug safety system. J Health Polit Policy Law 2013;38:545-71

15. Guidance document: Notice of Compliance with Condition (NOC/c). Ottawa (ON): Health Canada; 2005. Available: www .hc-sc.gc.ca/dhp-mps/prodpharma/applic-demande/guide-ld/compli -conform/noccg_accd-eng.php (accessed 2014 Feb. 12).

16. Lexchin J. Notice of compliance with conditions: a policy in limbo. Healthc Policy 2007;2:114-22.

17. Schultz WB. Bolstering the FDA's drug-safety authority. N Eng J Med 2007;357:2217-9.

18. Weeks C. Birth-control recall: Experts still unsatisfied with Health Canada despite investigation into delays. The Globe and Mail. 2013 Apr. 12. Available: www.theglobeandmail.com /life/health-and-fitness/health/birth-control-recall-experts-still -unsatisfied-with-health-canada-despite-investigation-into-delays /article11163040/ (accessed 2014 Feb. 12).

19. Risk Sciences International. Final report - review of Health Canada's actions in the recall of Alysena ${ }^{\mathrm{TM}} 28$. Ottawa $(\mathrm{ON})$ : Health Canada; 2013. Available: www.hc-sc.gc.ca/ahc-asc/pubs/hpfb -dgpsa/2013-alysena-recall-rappel/index-eng.php\#a243 (accessed 2014 Feb. 12)

20. Rodwin MA, Abramson JD. Clinical trial data as a public good JAMA 2012;308:871-2.

21. Dhalla I, Laupacis A. Moving from opacity to transparency in pharmaceutical policy. CMAJ 2008;178:428-31.

22. Zarin DA, Tse T. Moving toward transparency of clinical trials Science 2008;319:1340-2.

23. Food and Drug Administration Amendments Act (FDAAA) of 2007, Pub. L. No. 110-85, § 801, 121 Stat. 823, 904-22 (2007).

24. European Commission. Communication from the Commission Regarding the guideline on the data fields contained in the clinical trials database provided for in article 11 of directive 2001/ $20 /$ ec to be included in the database on medicinal products provided for in article 57 of regulation (EC) No 726/2004. Official J Eur Union 2008; 168.

25. Publication and access to clinical-trial data. Policy/0070: draft for public consultation. European Medicines Agency; 2013. Available: www.ema.europa.eu/docs/en_GB/document_library /Other/2013/06/WC500144730.pdf (accessed 2014 Feb. 12).

26. Health Canada's clinical trials database. Ottawa $(\mathrm{ON})$ : Health Canada; 2013. Available: www.hc-sc.gc.ca/dhp-mps/prodpharma /databasdonclin/index-eng.php (accessed 2013 Dec. 16).

27. Prayle AP, Hurley MN, Smyth AR. Compliance with mandatory reporting of clinical trial results on ClinicalTrials.gov: cross sectional study. BMJ. 2012;344:d7373

28. Viergever RF, Ghersi D. The quality of registration of clinical trials. PLOS ONE 2011;6:e14701

29. Dickersin K. Rennie D. The evolution of trial registries and their use to assess the clinical trial enterprise. JAMA 2012;307:1861-4.

30. Doshi P, Jefferson T, Del Mar C. The imperative to share clinical study reports: recommendations from the tamiflu experience. PLoS Med 2012;9:e1001201.

31. Notice: launch of phase II of the summary basis of decision project Ottawa (ON): Health Canada; 2011. Available: www .hc-sc.gc.ca/dhp-mps/prodpharma/activit/announce-annonce/sbd notice launch phaseii_smd lance avis-eng.php (accessed 2013 Dec. 16).

32. Tafuri G, Trotta F, Leufkens HGM, et al. Disclosure of grounds of European withdrawn and refused applications: a step forward on regulatory transparency. Br J Clin Pharmacol 2013; 75:1149-51.

33. FDA transparency initiative: draft proposals for public commen regarding disclosure policies of the US Food and Drug Administration. Silver Spring (MD): US Food and Drug Administration 2010. Available: www.fda.gov/downloads/AboutFDA/Transparency /PublicDisclosure/GlossaryofAcronymsandAbbreviations/UCM 212110.pdf (accessed 2014 Feb. 12)

34. Herder M. Toward a jurisprudence of drug regulation. J Law Med Ethics. In press.

35. Clarke A, Deeks JJ, Shakir SAW. An assessment of the publicly disseminated evidence of safety used in decisions to withdraw medicinal products from the UK and US markets. Drug Saf 2006;29:175-81

36. An act to amend the Food and Drugs Act and to make consequential amendments to other Acts, 2008, 39th Parliament, 2nd Sess.

37. Herder M. Unlocking Health Canada's cache of trade secrets: mandatory disclosure of clinical trial results. CMAJ 2012;184 194-9.

38. Steinbrook R. The European Medicines Agency and the brave new world of access to clinical trial data. JAMA Intern Med 2013;173:373-4.

39. Eichler H-G, Pétavy F, Pignatti F, et al. Access to patient-leve trial data - a boon to drug developers. N Engl J Med 2013;369: 1577-9.

40. Nisen P, Rockhold F. Access to patient-level data from GlaxoSmithKline clinical trials. N Engl J Med 2013;369:475-8.

41. North American Free Trade Agreement Between the Government of Canada, the Government of Mexico and the Government of the United States. 17 Dec. 1992, Can. T.S. 1994 No. 2, 32 I.L. M. 289 (entered into force Jan. 1, 1994)

42. Ho CM. Access to medicine in the global economy: international agreements on patents and related rights. New York (NY) Oxford University Press; 2011.

Affiliations: Faculties of Medicine and Law (Herder), Health Law Institute, Dalhousie University; Schulich School of Law (Gibson), Dalhousie University; Department of Pediatrics (Graham), Faculty of Medicine, Dalhousie University, Halifax, NS; School of Health Policy and Management (Lexchin), York University; Emergency Department (Lexchin), University Health Network; Department of Family and Community Medicine (Lexchin), University of Toronto, Toronto, Ont.; School of Population and Public Health (Mintzes), University of British Columbia, Vancouver, BC

Contributors: Matthew Herder helped conceive the article's focus on Bill C-17 (with Elaine Gibson), wrote the first draft of the article, and coordinated revisions among coauthors and in response to peer review. Elaine Gibson participated in conceptualization of the article's focus and design, and provided critical revisions. Janice Graham contributed to the acquisition, analysis and interpretation of data, to drafting the article and to critically revising the content. Joel Lexchin helped gather the data for the article and contributed to the revisions of the manuscript. Barbara Mintzes contributed to the conception of the article, interpretation of data and revisions of article drafts. All of the authors gave final approval of the version submitted for publication. 